\title{
PANORAMA DA LUDICIDADE NA POESIA VISUAL
}

\author{
Geraldo Augusto Fernandes \\ Doutor em Letras - Literatura Portuguesa - pela Universidade de São Paulo (USP) \\ Professor Adjunto da Universidade Federal do Ceará (UFCE) \\ geraldoaugust@uol.com.br
}

\section{RESUMO}

A poesia visual tem sido apresentada e comemorada, na maioria das vezes, apenas como recurso ora pictórico, ora gráfico, que o artista escolhe para se manifestar. Através dos tempos, o artifício da visualidade na poesia tem tido objetivos outros que não somente aqueles: nas épocas primevas, tinha sentido religioso e mágico; na Idade Média, sua preocupação passa a ser mais ligada à destreza e agudeza do poeta, para atingir seu ápice no Barroco e no Concretismo. Calcadas na tradição, as carmina figurata têm oferecido ao poeta e ao utente um manancial de possibilidades tanto estéticas como de deleite. Centradas no significante da palavra, a leitura que sobressai dos poemas "em forma de" tem instigado estudos unindo a questão mágico-religiosa à estética.

Palavras-chave: poesia visual, ludicidade, tradição, inovação.

\section{ABSTRACT}

Visual poetry has been presented and celebrated, most of the time, only as a pictorial or graphic resource that the artist chooses to manifest. Through the ages, the artifice of visuality in poetry has had goals other than those: in primeval times, it had a religious and magical sense; in the Middle Ages, its concern becomes more connected to the poet's skill and acuteness, to reach its apex in the Baroque and Concretism. Drawing on tradition, the carmina figurata have offered the poet and the reader a wealth of both aesthetic and delightful possibilities. Centered on the signifier of the word, the reading that emerges from the poems "in the form of" has instigated studies linking the magic-religious question to aesthetics.

Keywords: visual poetry, ludicity, tradition, innovation. 


\section{Introdução}

A poesia visual não foi uma "invenção" contemporânea. Ela surgiu já na Grécia clássica e se expandiu por todo o território europeu, até atingir seu ápice na Modernidade. Naquela época, a intenção dos poetas era criar um sentido mágico e religioso. Já na Idade Média, alia-se ao sentido mágico e religioso a questão da habilidade e criatividade do poeta. Unindo a palavra verbal à imagem, os poemas figurados trazem ao apreciador uma facilidade de compreensão e prazer, comparáveis, sim, ao prazer do poema escrito. Daí que, além de qualquer objetivo que pretende o artista, o poema visual tem por princípio primeiro a ludicidade - atitude tão comum ao ser humano.

Roger Caillois, em Los juegos y los hombres. La máscara y el vértigo, dá ênfase à palavra ludus por reunir em si dois princípios caros a este estudo: a poesia como jogo e a inventividade:

Su capacidad primaria de improvisación y de alegría, a la que yo llamo paidia, se primeiro a ludicidade - atitude tão comum ao ser humano.

conjuga con el gusto por la dificultad gratuita, a la que propongo llamar ludus, para llegar a los diferentes juegos a los que sin exagerar se puede atribuir una virtud civilizadora. (...) El ludus da ocasión a un entrenamiento, y normalmente desemboca en la conquista de una habilidad determinada, en la adquisición de una maestría particular, en el manejo de tal o cual aparato o en la aptitud de descubrir una respuesta satisfactoria a problemas de orden estrictamente convencional (CAILLOIS, 1986, 65-68).

Especificamente quanto à poiesis, Johan Huizinga a vê como uma função lúdica, pois 
ela se exerce no interior da região lúdica do espírito, num mundo próprio para ela criada pelo espírito, no qual as coisas possuem uma fisionomia inteiramente diferente da que apresentam na 'vida comum', e estão ligadas por relações diferentes das da lógica e da causalidade. Se a seriedade só pudesse ser concebida nos termos da vida real, a poesia jamais poderia elevar-se ao nível da seriedade. (...) Em sua função original de fator das culturas primitivas, a poesia nasceu durante 0 jogo e enquanto jogo - jogo sagrado, sem dúvida, mas sempre, mesmo em seu caráter sacro, nos limites da extravagância, da alegria e do divertimento. Até aqui não se trata da satisfação de qualquer espécie de impulso estético. A ordenação rítmica ou simétrica da linguagem, a acentuação eficaz pela rima ou pela assonância, o disfarce deliberado do sentido, a construção sutil e artificial de frases, tudo isto poderia consistir-se em outras tantas manifestações do espírito lúdico (HUIZINGA, 1993, 133-149).

E como se desenvolve esse novo espírito lúdico-poético? Nas palavras de Johan Huizinga, ele unirá técnicas do fazer poético, tais como ritmo, rima e métrica, ao impulso e expressão estética. O espírito poético aventado pelo estudioso alemão vê a poesia como um jogo lúdico em que as palavras e os sons deverão ser condizentes com o tema e a forma - ela principalmente - com que quer expressar o "eu-lírico" (idem, 24). Além desses elementos "técnicos", o poeta criativo deve ser levado por um "arrebatamento" para Frobenius, a capacidade de criar, em qualquer indivíduo criativo, nasce de um estado emocional perante qualquer fato que será, então, condensado pela expressão poética e artística (idem, 15-26). O poeta inventivo também passa por uma espécie de treinamento num jogo, na concepção de Roger Caillois: no manejo de um aparato ou uma atitude que satisfaça problemas de ordem convencional (CAILLOIS, 1986, 24). O "poietes" é, então, um técnico em que a inspiração é um Dom, aprimorado pelo ato de fazer poesia. 
Johan Huizinga afirma que, na Idade Média, os contemporâneos admiravam mais os poetas do que os pintores, mesmo que aqueles, no parecer hodierno, fossem superficiais, monótonos e enfadonhos, por repetirem ad nauseam os mesmos temas e imagens. Explica que isso se dava porque as palavras e as imagens têm uma função estética diferente da pintura.

O contemporâneo vibrará com as palavras do poeta porque o pensamento que ele exprime faz parte integrante da sua vida e parecer-lhe-á tanto mais interessante quanto mais brilhante for a forma. (...) Mas se esse pensamento estiver já gasto e não corresponder às preocupações da alma, nenhum valor se the atribuirá excepto o da forma. E essa tem, indubitavelmente, extrema importância (HUIZINGA, 1993, 284285).

É na forma, portanto, que os poetas, nas palavras do próprio estudioso holandês, encontrarão um meio de exaltação do belo (idem, 290). E é com esse artifício formal, ao exprimir uma simples imagem ou cena, ou ainda um sentimento ingênuo, que eles revelarão seu vigor. É nos pequenos poemas que a beleza se mostrará, a exemplo dos rondós e baladas medievais, para citar apenas uma referência, pois "a graça depende da sonoridade, do ritmo e da imagem.

Baseado nos estudos de Johan Huizinga, Roger Calliois, Paul Zumthor e teóricos da Poesia Concreta, pretende-se pontuar este elemento básico da poesia visual - a ludicidade. Calcados no lúdico, serão trazidos, a seguir, alguns poemas que fogem às premissas das artes poéticas, tanto as antigas quanto as medievas, bem como as barrocas e concretistas. O interesse estará centrado apenas na demonstração de como alguns poetas - considerados "criativos" ou "inovadores" - transgrediram o comum e criaram 
composições que se destacam justamente ora pela engenhosidade ora pela ludicidade. Dessa forma, a mostra que segue é apenas descritiva.

\section{Os precursores}

Na Antiguidade, Teócrito de Siracusa (308-240 a. C.), Símias de Rodes (300 a. C.) e, já na Alta Idade Média, Publílio Optatiano Porphyrio (séc. IV) e Rábano Mauro (780-826) compuseram vários poemas figurados - carmina figurata, em latim, ou technopaígnia, em grego - que retratam uma espécie maneirística de disposição formal e conteudística dos

significantesi, e podem ser considerados precursores de um tipo de poesia visual que, parece, tem inspirado poetas não só medievais, mas também renascentistas, barrocos e concretistas-experimentalistas. Poder-se-ia, então, tomá-los como

o ponto onde surgiria o primeiro programa, o seu ponto zero, [o qual] situar-se-ia na região problemática da invenção que, não sendo possível, dizem-nos, a partir do nada, só começa a poder afirmar-se como tal a partir dum contexto histórico (HATHERLY, 1983, 121).

Essa maneira de compor poemas em forma de $e^{i i}$ não passou despercebida pelos poetas concretos, diga-se de passagem. Fazendo referências a Símias de Rodes e unindoo a Mallarmé e Apollinaire, escreve Charles Boultenhouse, poeta norte-americano:

Um poema configurado é sempre novo, porque faz volver o poema à simplicidade original da linguagem escrita, à experiência primitiva, vívida, imediata e mágica de um som combinado com um signo. Pode o som ser disposto em muitos ritmos e evocar muitas imagens, mas a dupla experiência de olhar e ler nos dá a sensação de 
que tudo está recomeçando do nada. Apollinaire a Mallarmé, Mallarmé ao antigo grego Símias. Ser novo, no sentido do poema configurado, é sinal inconfundível de espírito de vanguarda - e, na verdade, de todas as formas de literatura que a antiguidade nos legou, esta é a única que permanece vanguarda ainda hoje (Apud CAMPOS, 1975, 130).
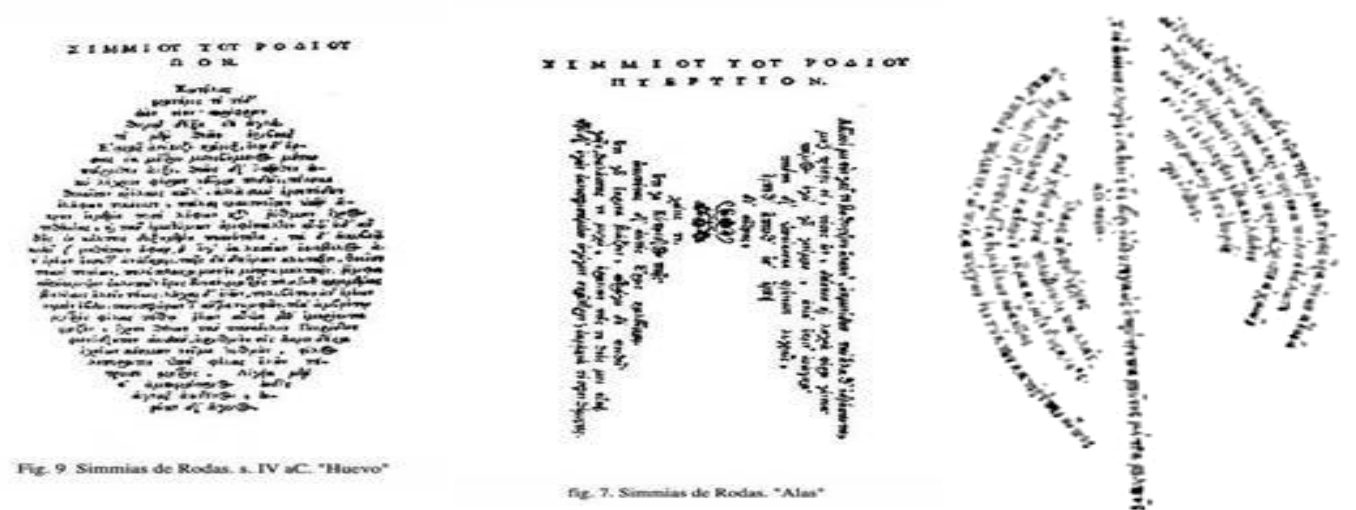

Símias de Rodes (séc. IV a. C.), da esquerda para a direita: “Ovo”, “Asas de Eros" e "O

Machado".

"O ovo" pode ser considerado o primeiro poema visual composto no mundo ocidental; data de 300 a. C., durante o reinado de Ptolomeu I. Em uma ilha chamada Simi, a nordeste de Rodes, o poeta Símias de Rodes compôs um poema em forma de ovo, cuja leitura simultânea parte da 1aㅡ linha, que é o 1 으 verso, seguindo à última, que é o segundo verso; a 2a linha é o terceiro verso, e assim sucessivamente, até o último verso, que ocupa o eixo central do poemaiii. 

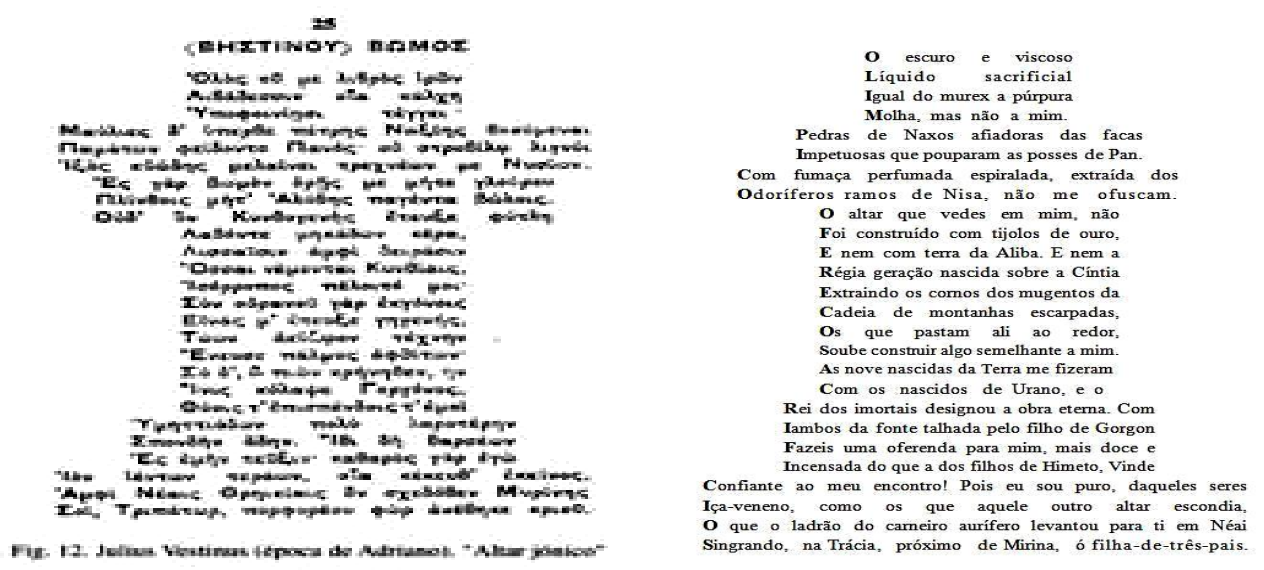

Julius Vestinas (época de Adriano, séc. IV d. C.) “Altar jônico”. Trad. de Juliana Di Fiori Pondian

O poema Altar jônico de Julius Vestinus é claramente uma imitação do Altar dórico de Dosíadas, outro poema visual grego. Ambos os poemas apresentam reciprocidades não somente em relação à expressão (a forma de altar), mas também no que diz respeito ao conteúdo. No poema de Julius Vestinus, lê-se menção ao altar de Lemnos e o episódio de Filoctetes e da serpente ao final do poema.

\section{Alta Idade Média}

Na Alta Idade Média, Publílio Optatiano Porphyrio (séc. IV) e Rábano Mauro (780826) compuseram vários poemas visuais, os quais poderiam ser tomados como "o ponto onde surgiria o primeiro programa, o seu ponto zero, [o qual] situar-se-ia na região problemática da invenção que, não sendo possível, dizem-nos, a partir do nada, só começa a poder afirmar-se como tal a partir dum contexto histórico" (HATHERLY, 1983, 121). 
Um exemplo desse tipo de poesia figurada é o cálice (poculum) $^{\mathrm{iv}}$, poema "desenhado" com as palavras que remetem ao objeto sobre o qual o provável poeta medieval se propôs versar:

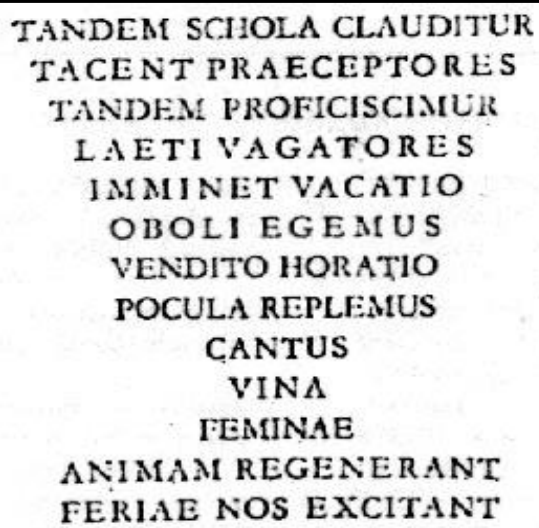

Ao construir seu poema, o poeta vincou o campo semântico próprio do cálice e daquilo que pode conter: chegam as férias, fecham-se as escolas, calam-se os professores, saem os alegres errantes a cantar, beber, conhecer as mulheres, para regenerar a alma com aquilo que os excita nos dias de festa: um cálice repleto de vinho ${ }^{v}$. Permite ao interpretante, de forma didática, não só ver a imagem formada pelas palavras, mas também empenho "en la elegancia, en el matiz verbal, en la práctica específica y operativa del texto" (ZÁRATE, 1978, 354).

Sob influência de Venâncio Fortunato, do século VI, a produção do monge beneditino germânico Hrabanus Maurus se notabiliza por tratar a temática da criação divina de forma muito particular. Seu conjunto de 28 poemas, intitulados de De Laudibus Sanctae Crucis é enigmaticamente cifrado como em disposição geométrica mesclando imagem e texto verbal. Suas possibilidades de leitura são múltiplas porque os versos são inseridos de modo independente, pode-se ler o texto como um todo ou em quadros separados que, por sua vez, encerram poemas à parte. Ele construiu um sistema de 
código de 36 versos que continham 36 letras espacializadas uniformemente em quadrantes. Sua linguagem era simples e logo se tornou populari

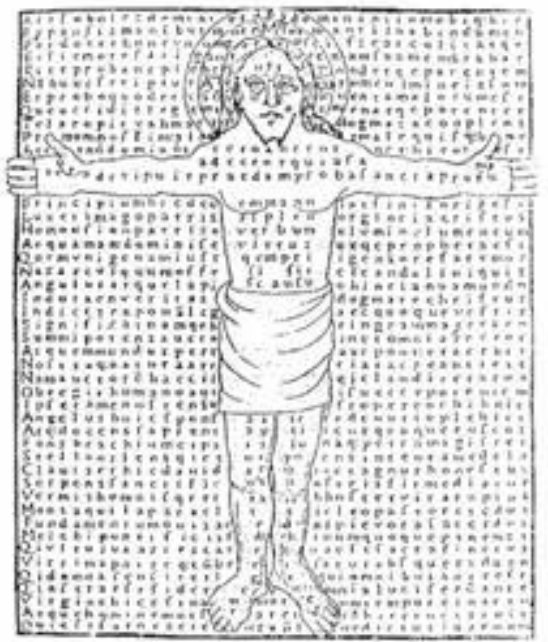

Poema de Rábano Mauro

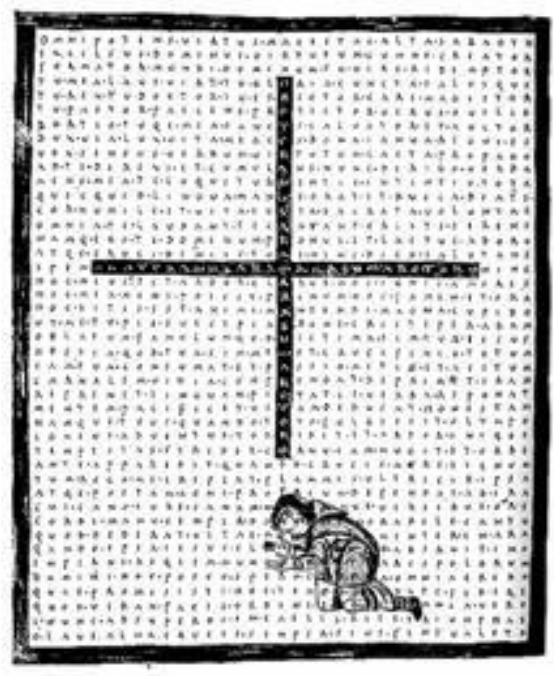

Poema de Rábano Mauro

\section{Na poesia provençal, a surpresa maneirista}

Alguns trovadores provençais, à luz do conceito de originalidade, destacam-se de forma evidente. Cerveri de Girona/Guilhem de Cervera (...1259-1285...) compôs uma canção distribuída em estrofes de versos de uma só sílaba, com alternância de outros versos com duas sílabas. Tal composição foge à rigidez de princípio, ou de princípios, que norteava as composições poéticas, assim como prescreviam as Leys $d^{\prime}$ amors ${ }^{\text {vii }}$. Na edição de Martín de Riquer, a canção assim se apresenta:

Us
an
chan,
pe-




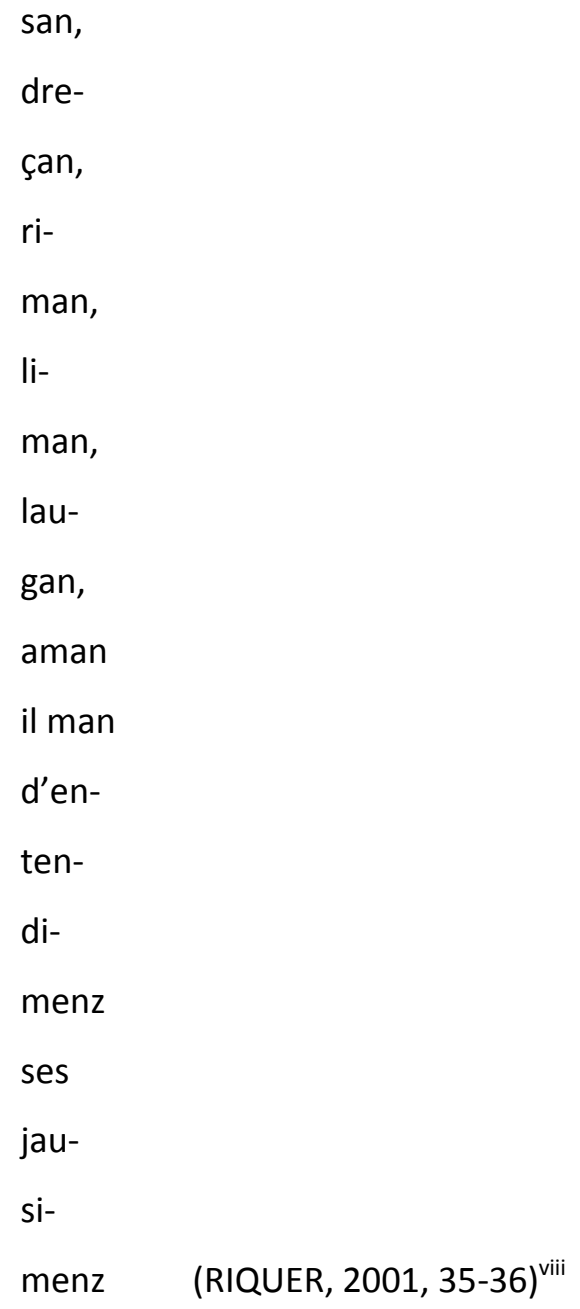

Girona não foi feliz apenas na disposição de sua canção, mas também na melodia, o que é tautológico, já que os poemas à época eram para ser cantados. Realiza-se a intenção pontual de evidenciar as terminações em "an", cuja musicalidade não só pode ter agradado a audiência como uniu forma e fundo: coloca no seu poema a definição de poeta, que é dispor, rimar, limar, louvar e amar. Para Martín de Riquer, Cerveri cultivou, assim como Arnaut Daniel, o "trobar ric", em que "alcanza a veces momentos muy logrados (idem, 1563) e "aunque por este camino llega a la extravagancia de componer una canción con versos de una y dos sílabas" (idem, 1563).

Sabe-se que os trovadores provençais forneceram a seus sucessores os meios e artifícios para a criação poética própria de cada região europeia. Na Galiza, os trovadores 
galego-portugueses foram beber naqueles antepassados para criarem o tipo de poesia que seria característico da Península. À parte as cantigas de amigo, consideradas pelos estudiosos como autóctones, pois revelariam o espírito, a alma do lado ocidental peninsular, a maioria das cantigas de amor e as de maldizer e de escárnio seria a continuação da produção provençal.

\section{Nos cancioneiros galego-portugueses, a quebra dos cânones}

Nos cancioneiros galego-portugueses, a inovação desponta em alguns trovadores que, se no tema permaneciam fiéis aos cânones, na forma ousavam. No Cancioneiro da Ajuda $^{i x}$, encontra-se um descordo ${ }^{x}$ singular de Nuneannes Cerzeo, de número 389, que assim se apresenta na lição de Carolina Michaëlis de Vasconcelos:

\footnotetext{
Agora me quer'eu ja espedir da terra, e das gentes que i son, u mi Deus tanto de pesar mostrou, e esforçar mui ben meu coraçon, e ar pensar de m'ir alhur guarir. E a Deus gradesco porque m'én vou.

Ca [a] meu grad', u m'eu d'aqui partir', con seus desejos non me veeran chorar, nen ir triste, por ben que eu nunca presesse; nen me poderan dizer que eu torto faç'en fogir d'aqui u me Deus tanto pesar deu.
}

Pero das terras averei soidade 
de que m'or'ei a partir despagado;

e sempr'i tornará o meu cuidado

por quanto ben vi eu en elas ja;

ca ja por al nunca me veerá

nulh'om(e) ir triste nen desconortado.

E ben digades, pois m'én vou, verdade,

se eu das gentes algun sabor avia,

ou das terras en que eu guarecia.

Por aquest'era tod', e non por al;

mais ora ja nunca me será mal

por me partir d'elas e m'ir mia via.

Ca sei de mi

quanto sofri

e encobri

en esta terra de pesar.

Como perdi

e despendi,

vivend'aqui,

meus dias, posso-m'én queixar.

E cuidarei,

e pensarei

quant'aguardei

o ben que nunca pud'achar.

E[s]forçar-m'ei,

e prenderei

como guarrei

conselh'agor', a meu cuidar.

\section{Pesar \\ d'achar \\ logar \\ provar}



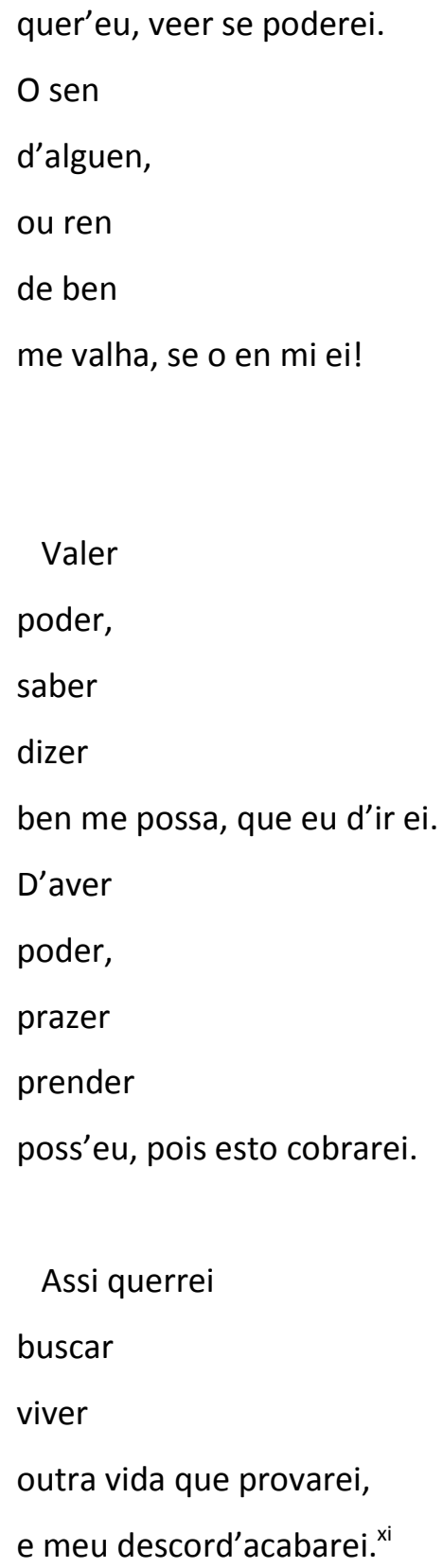

O que chama a atenção nessa peça é a desigualdade com que se montam e se distribuem as estrofes e as rimas, além de vários enjambements nas sextilhas, bem como na cauda, em que esse processo fica mais evidente. Essa dissimetria, diga-se de passagem, não é novidade. Vimos nos exemplos anteriores - com os provençais - que esse artifício, apesar de raro, existiu e foi resultado de uma releitura que todos os poetas "antenados" promoveram ao remontarem ao passado. 
Feito para o canto, o descordo de Cerzeo traz, também, um ritmo diferenciado que deve ter causado estranhamento e, ao mesmo tempo, deleite aos ouvintes. Acrescentese que, além da irregularidade própria deste subgênero poético, a partida é condensada no último verso que fecha com a palavra "descordo", denominação do tipo de poesia que criou para expressar seu sentimento. Se esse tema - o da partida - não é novo, aliás, é recorrente na literatura medieval, o exemplo desse poema serve para destacar como, numa forma assimétrica em estrutura e ritmo, um espírito poético inquietante se serve de recursos diferenciadores para destacar sua individualidade poética. Registre-se ainda que esse poema dialoga também com o de Vestinus ("Altar Jônico"), lido acima.

\section{A poesia visual no Cancioneiro Geral de Garcia de Resende}

Se no Cancioneiro de Resende não são novidades os acrósticos, os anagramas e o pantogramatismo, inusitado é encontrar um único labirinto criado por Fernão da Silveira, diferente mais pela forma do que pelo tema declamado. O poema é "Senhora, graciosa, discreta, eicelente" e desperta atenção pela sua estrutura formal. O poema assim se apresenta já na primeira edição do Cancioneiro Geral (1516) e vem intitulado "Outra sua": 


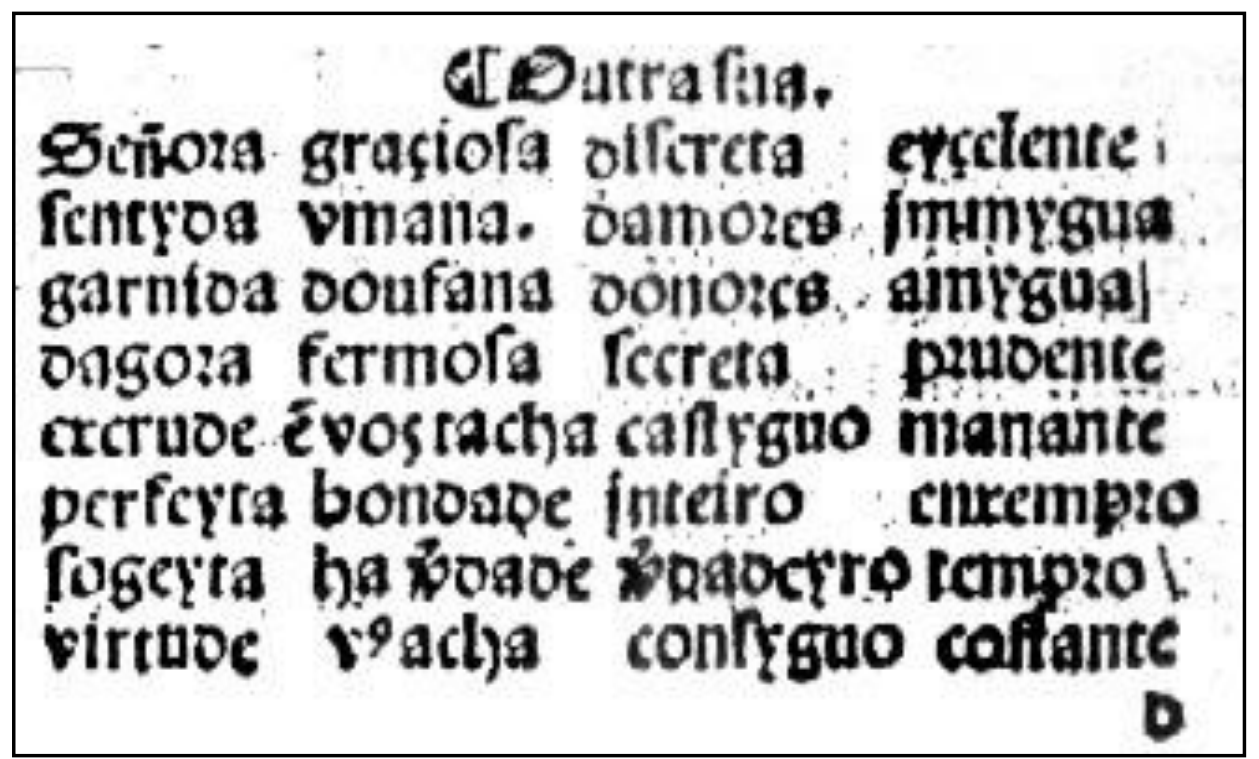

Transcrição em português moderno

$\begin{array}{lll}\begin{array}{l}\text { Senhora graciosa, } \\ \text { sentida, humana, }\end{array} & \text { discreta, } & \text { eicelente, } \\ \text { garnida d'oufana, } & \text { d'honores } & \text { immiga, } \\ \text { d'agora fermosa, } & \text { secreta, } & \text { prudente, } \\ \text { excrude em vós tacha } & \text { castigo } & \text { manante, } \\ \text { perfeita bondade, } & \text { inteiro } & \text { enxempro, } \\ \text { sogeita à verdade, } & \text { verdadeiro } & \text { tempro } \\ \text { virtude vos acha } & \text { consigo } & \text { costante }^{\text {xii }} .\end{array}$

Essa composição original é formada por quatro esparsas alinhadas verticalmente, o que, já aí, constitui uma fuga ao padrão do Cancioneiro: todas as esparsas dessa reunião de poemas são monostróficas. A disposição espacial dessas esparsas ocupa todo o branco da página e sua visualização destaca-se por estar o poema quase isolado das outras peças no fólio. Entende-se que, pelo som, pelo ritmo, pela sua construção binária - um som 
fraco, um forte, um fraco - o poema faz música com as palavras, agora que ela não é mais acompanhada por instrumentos musicais, até onde se sabe. A composição rítmica dos quatro primeiros versos, tanto na vertical quanto na horizontal, tem sonoridade acentuada para cima ou para a direita. Declamando-se os quatro últimos versos, a sonoridade é mais branda, para baixo ou para a esquerda. Além de brincar com a forma, o poeta enfrenta, então, um desafio novo característico do final de Quatrocentos: aliar música à poesia, já que, depois do Trovadorismo, aquela já não fazia parte da composição poética.

\section{Barroco: imagens e formas do seiscentos português}

Nota-se na coletânea da Fênix Renascida, bem como no Postilhão de Apolo, que uma das preocupações precípuas dos poetas barrocos era a questão da forma, comparada com "as linhas curvas e contorcionadas da arquitectura de Seiscentos (A POESIA, 1968, VII)" em oposição à arquitetura retilínea do período anterior. Para o autor da recopilação, "as estátuas e pinturas [são] sacudidas de fundas emoções" e “contrastam com as de apolínea serenidade da época anterior (idem, VII)". Teria o artista barroco transposto para a obra literária a mesma forma rebuscada da arquitetura, da pintura e das estátuas, assim como, no fim do medievo, a engenhosidade poética pode ser comparada ao estilo gótico ${ }^{\text {xiii }}$, um estilo que antevê o próprio estilo barroco, posto que também rebuscado.

Relativamente à arte poética, como toda a dualidade que está ligada ao Barroco, conviviam dois modos de conhecimento, o cultismo ou gongorismo (de Luís de Góngora, 1561-1627, espanhol) - valorização de forma e imagem, jogo de palavras, uso de 
metáforas, hipérboles, analogias e comparações; e o conceptismo ou quevedismo (do também espanhol Francisco de Quevedo, 1580-1645) - valorização do conteúdo/conceito, jogo de ideias através do raciocínio lógico. Há o uso da parábola com finalidade mística e religiosa.

Enquadram-se, portanto, os poemas visuais barrocos no modo cultista de expressão, pois além de jogo, nele os poemas valorizam a forma e a imagem. Ana Hatherly, em comunicação durante o II Colóquio Internacional de Discursos e Práticas Alquímicas (1999), intitulada "O prodígio da língua", diz que

através da escrita poética, a palavra reencontra a sua original consistência de matéria prima e, se para os velhos alquimistas, a pedra filosofal é uma pedra que não é pedra, para os velhos poetas, a palavra não é só palavra: tanto no seu todo como nos seus elementos constitutivos, a palavra, sobretudo escrita, surge como uma representação do mundo como enigma, enigma que ela simultaneamente revela e mimeticamente recria (HATHERLY, 2002).

Diz ainda que essa espécie de "cosmologia poética" é particularmente nítida na Europa, durante o Barroco, "quando se produz uma enorme confluência de saberes antigos em que predomina um pensamento hermético aliado a um culto do prodigioso, do fantástico e do misterioso, que incendeia as sensibilidades da época e que a modernidade de então incorpora nos objectos-actos que produz" (idem). Ana Hatherly analisa, em sua exposição, os Anagramas Poéticos, assim manifestando-se:

construções que se baseiam em fundamentos teóricos que, em parte chegaram até nós, em que a língua, ou se quisermos, a palavra, e até a letra (não se usava ainda a designação de fonema) como mais tarde viria a acontecer no Concretismo, surgem como puros signos, sinais autónomos, substantivos, que, no entanto, se integram no 
sistema geral duma representação múltipla: por um lado, como representação codificada do sistema verbo-voco-visual a que pertencem; por outro, como representação dum universo de significação reservado, parcialmente secreto, o qual, por sua vez, é um símile (embora imperfeito) do universo geral que é o mundo da criação, pois se o mundo é um labirinto de Deus, como dizia o Padre Nieremberg na esteira de Plotino, esse mundo é um livro, onde a criação está escrita (idem).

Em sua comunicação, Hatherly apresenta poemas visuais de Luís Nunes Tinoco, "um notável poeta-pintor-calígrafo português do século XVII" (idem), que montou uma coleção de anagramas poéticos em honra da Rainha D. Maria Sofia Isabel, segunda esposa de D. Pedro II, coletânea que foi intitulada A Feniz de Portugal Prodígiosa (manuscrito de 1678). O Anagrama é "um dos textos-visuais típicos do período barroco escolhido para ilustrar esses princípios", neles se "pode verificar a complexa origem e a complexa prática desses enigmáticos textos-visuais que a sua construção e a sua descodificação exigem" (idem). Remete a autora a seu livro A Experiência do Prodígio, em que dispõe uma antologia de textos visuais dos séculos XVII e XVIII. Neles, "verifica-se que o fundamento teórico desses textos repousa numa concepção esotérica da escrita que se apoia numa tradição que, nalguns casos, é mantida e noutros transformada, pois o pacto lúdico que então passa a dominar sobrepõe-se por vezes aos ecos de um passado que assim se dessacraliza" (idem).

Tendo por base essa comunicação de Ana Hatherly, segue um anagrama visual, de Luís Nunes Tinoco, em que a louvação à Rainha Maria Isabel Sofia aparece nas imbricadas disposições das letras de seu nome. Outro anagrama é a "Pyramide Solenne", de Francisco Manuel de Melo. 


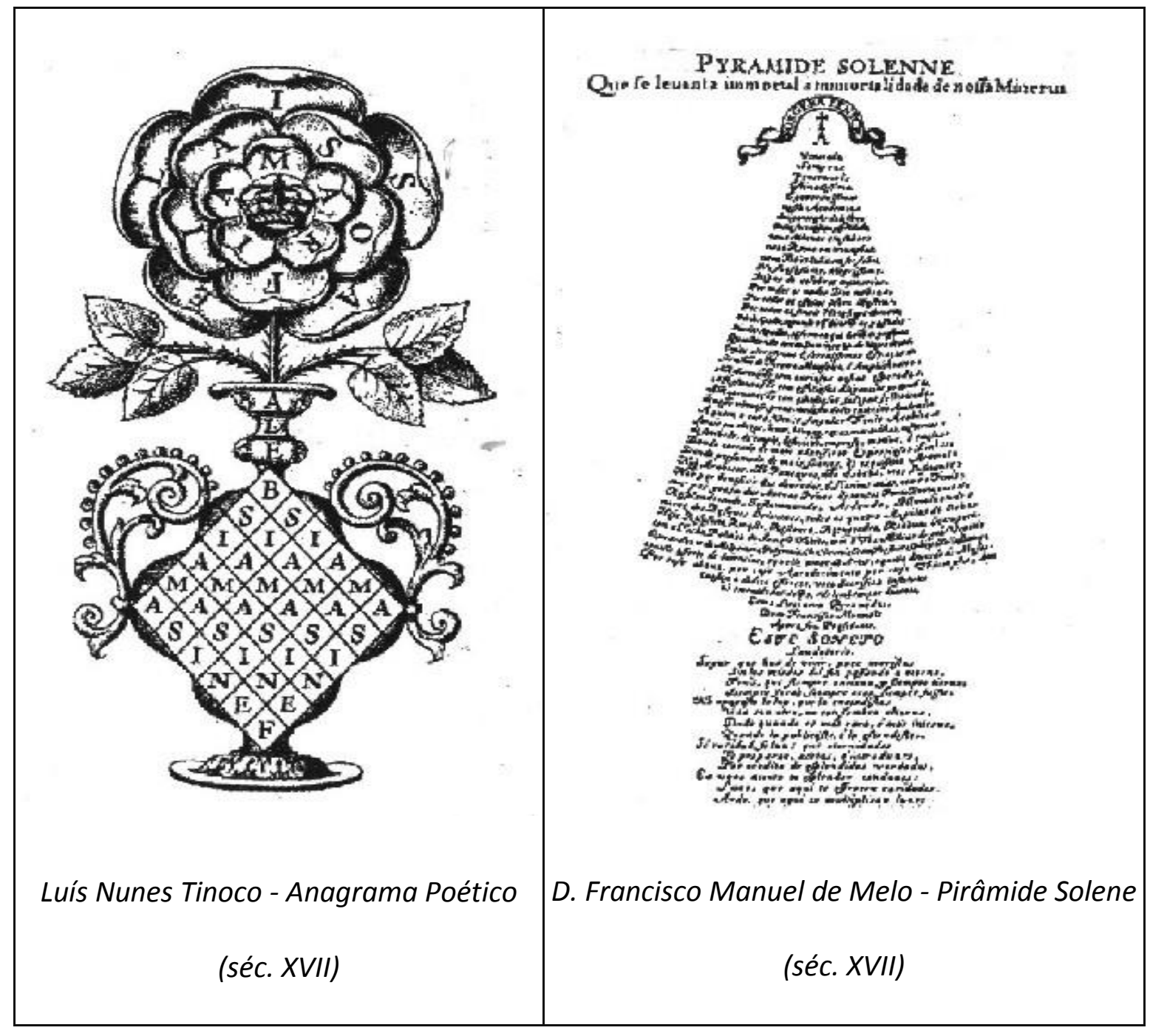

\section{Do Barroco ao Modernismo: nada de inovador?}

A resposta para tal pergunta é óbvia: tudo de inovador. O grande progresso que a Era Moderna proporcionou em todas as áreas do conhecimento inclui as Artes de qualquer veio. Pense-se, pelo menos na Europa, no desejo romântico de retorno às origens históricas que, para os poetas e escritores, estavam na Idade Média. Já o Modernismo, no início do século XX, procurou, de chofre, estigmatizar tudo o que era passado para incorporar, nas suas emanações artísticas, a velocidade, o dinamismo, a máquina. 
Em Portugal, nada foi diferente disso tudo o que se relatou sobre o Modernismo, mas lá se puderam sentir as mudanças com maior rapidez, uma vez que as revoluções vanguardistas aconteciam na Europa - em Paris, Praga, Roma. Em 1917, poetas modernistas portugueses realizam um "espetáculo futurista", baseado no manifesto de Marinetti, em que a velocidade, o uso de símbolos da Matemática e da Música, além da destruição da sintaxe, para citar apenas alguns tópicos, avultam. Essa revolução pode ser constatada, por exemplo, na longa composição de Mário de Sá-Carneiro “Manucure” (SÁCARNEIRO, 1995, 135), na qual alterna versos com símbolos e fontes linotípicas, vocábulos de diferentes idiomas, e, com intensidade, a reprodução dos sons próprios da dinâmica da nova sociedade com seus carros e máquinas.

Excerto de "Manucure", de Mário de Sá-Carneiro

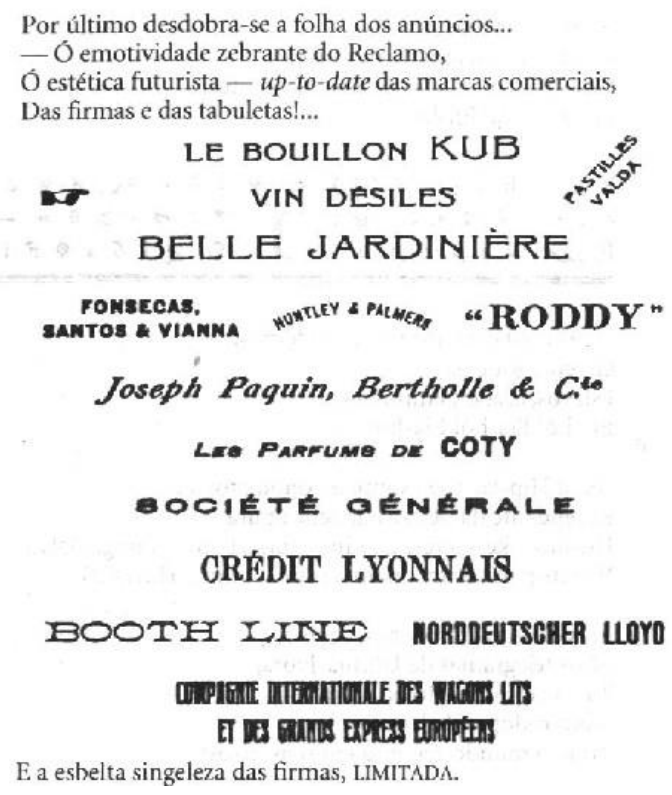

\section{Concretismo/Experimentalismo}


O choque que causou o surgimento do Concretismo no Brasil, em 1952, está ligado mais ao fato de os seus fundadores proporem uma desconstrução completa do lirismo, do que à importância exacerbada que deram ao signo. O poeta, ao dar importância à disposição das palavras no texto, estará observando os princípios do "rigor" na criação poética, o mesmo, conforme Melo e Castro, observado pelos poetas concretistas. Estes consideram a palavra "sob o aspecto 'físico, espacial e visual", organizando não um discurso, mas um objeto, dada a sua estrutura visual e sonora. É assim que o poema e o objeto concretos são criados de forma rigorosa e objetiva (MELO E CASTRO, 1973, 82-83).

O poema de Mallarmé "Un coup de dés", de 1897, pode ser considerado um precursor da moderna poesia visual, assim como os "Calligrames" de Apollinaire (1918), como se pode observar no seguimento:

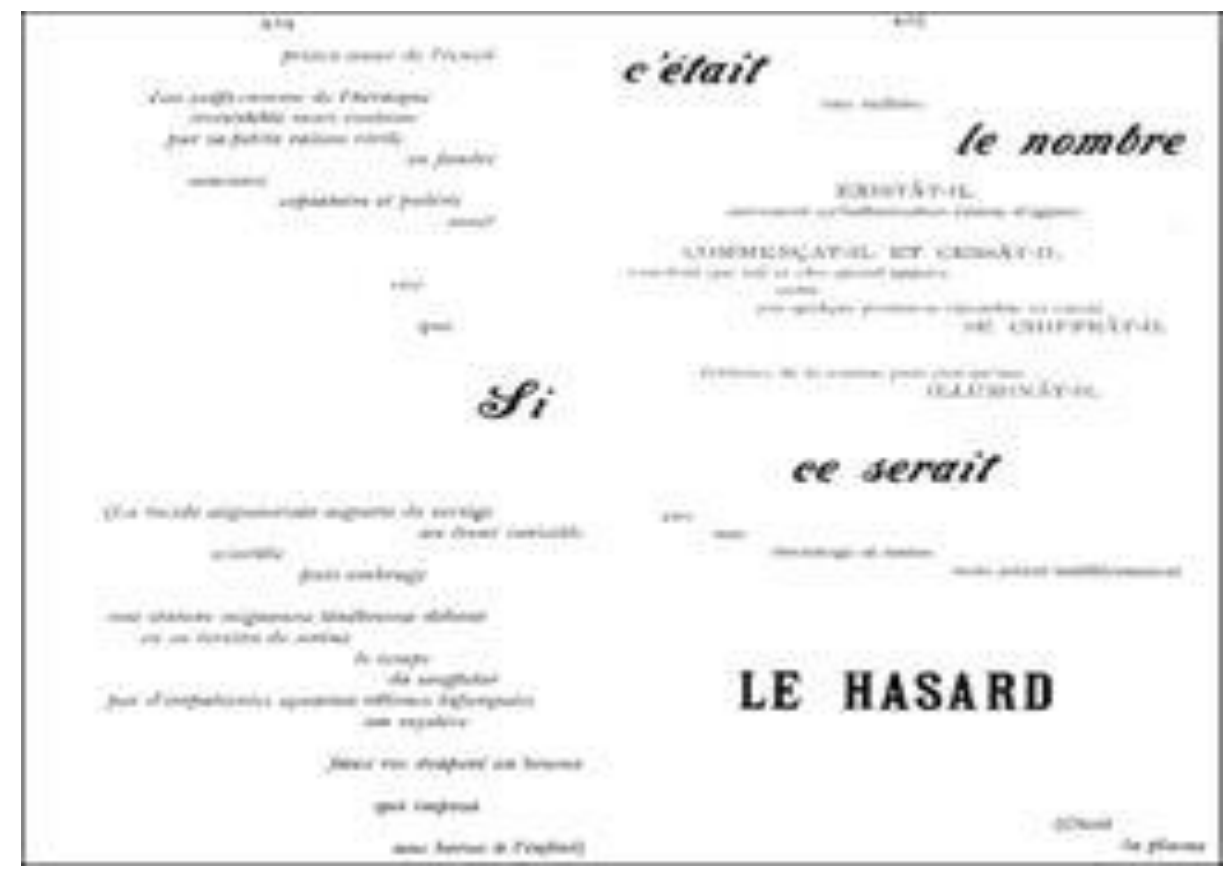

Um coup de dés, Mallarmé 


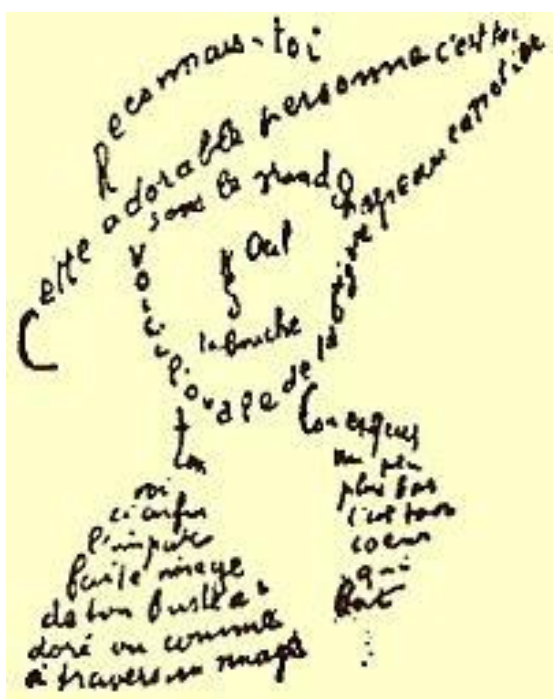

Calligrame de Apollinaire, 1918

Observe-se agora um antológico poema concretista, publicado no início do movimento:

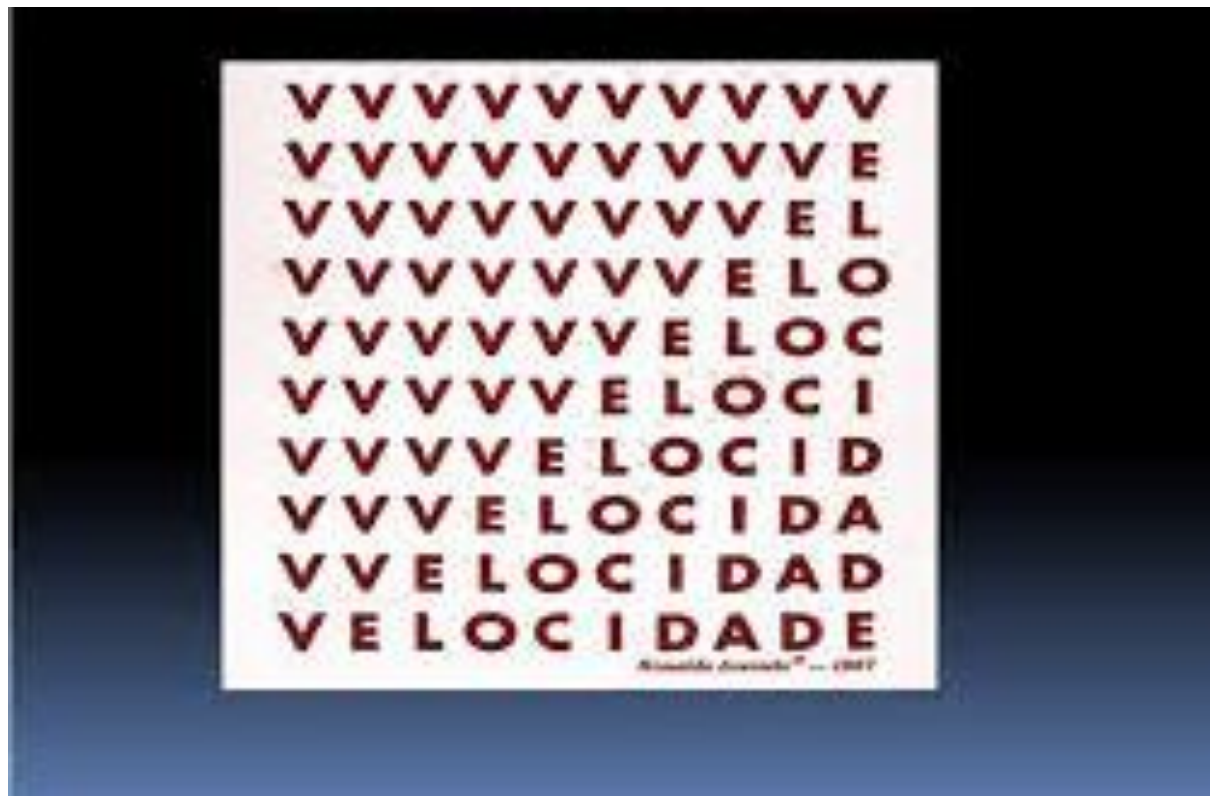

Velocidade, Ronaldo Azeredo, 1957

O poema "Velocidade", do poeta concretista brasileiro Ronaldo Azeredo, é amplamente divulgado em antologias didáticas. Nele, observa-se o jogo lúdico das letras 
e sua corrida, partindo do ponto-morto $\boldsymbol{V}$ até a completa - e veloz - formação da palavra velocidade. Unindo, visualmente, significante e significado. O poema, seguindo os preceitos da Poesia Concreta, visa a concretizar a dinâmica do objeto figurado ${ }^{\text {xiv }}$.

Seguindo as tendências do Concretismo, nasce em Portugal o Movimento Experimentalista, em 1964, no primeiro caderno da revista Poesia Experimental. Ao mesmo tempo em que, para os experimentalistas, a palavra tem valor substantivo - a "palavra-objeto", como a define -, ela é também um dos outros muitos meios de comunicação poética.

É a palavra, enquanto signo, que regerá a manifestação estética dos dois movimentos, Concretismo e Experimentalismo. Entretanto, enquanto a Poesia Concreta leva ao extremo o culto à parte significante do signo, a Poesia Experimental admite que, no plano do significado, o signo deverá ser mais explorado, perscrutando todos os campos semânticos possíveis. Uma clara demonstração disso é o ressurgimento de muitos dos valores estruturais do Barroco.

No século XX, os poetas concretistas e experimentalistas tentam dar nova expressão a formas já cultivadas nos movimentos passados. Essas formas são levadas ao leitor hodierno, para que as deglutam e a elas deem significado, conforme seu nível interpretante. É proposta das poesias modernas concretistas e experimentalistas que surja um diálogo entre o texto e o leitor, daí que a palavra, como significante, seja cada vez mais escoimada de significados.

O poeta experimentalista Melo e Castro, no seu poema "Pêndulo", faz com que a montagem de cada verso de sua poesia visual remeta o leitor à própria dinâmica do significado da palavra "pêndulo", movimento de balanço. Flagra, entretanto, apenas parte daquilo que o olhar capta no movimento pendular: um pêndulo sempre fará um 
movimento de $180^{\circ}$; o poeta registra apenas $90^{\circ}$, enfatizando sua ascensão à direita, partindo da lentidão inicial ao ápice ${ }^{\mathrm{xv}}$.

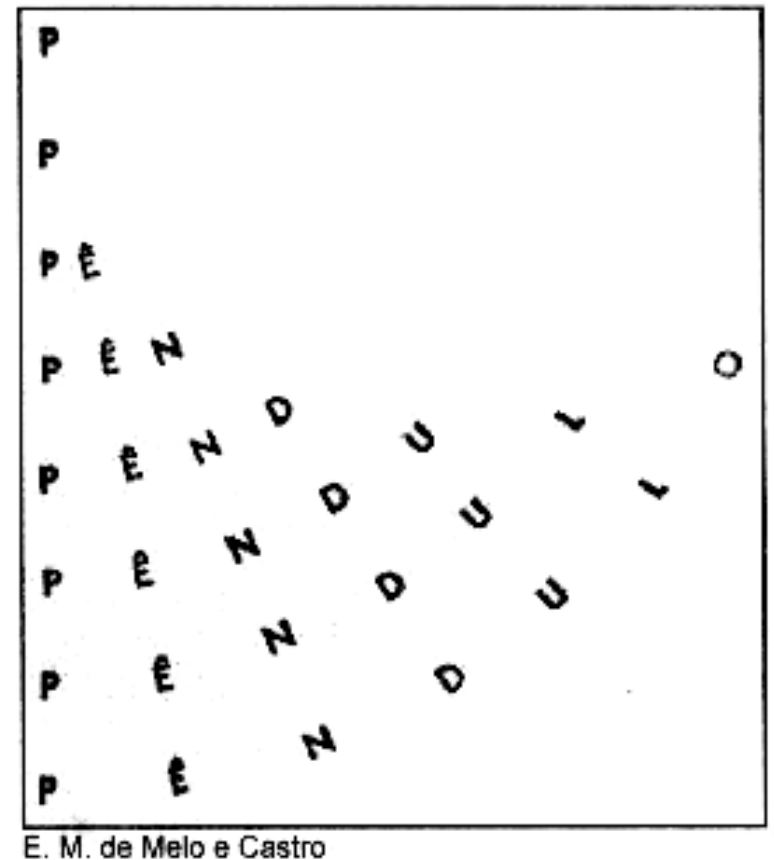

\section{Conclusão}

Viu-se que, de acordo com Johan Huizinga, especificamente quanto à poiesis, assim como em Roger Caillois, relativamente ao jogo, a poesia tem uma função lúdica, pois se exerce nessa região que é um mundo criado para ela, região diferente da lógica e da causalidade. A poesia, ainda conforme Huizinga, nasceu durante o jogo "nos limites da extravagância, da alegria e do divertimento", cuja construção "sutil e artificial de frases (...) poderia consistir-se em outras tantas manifestações do espírito lúdico" (HUIZINGA, 1993, 133-149).

É dessa forma que, ao se propor um estudo mais acurado da poesia visual, a questão da ludicidade deveria ser acrescida às de releitura da tradição, ato religioso ou ato puramente estético. Parece que, por exemplo, no ensino desse tipo de poesia é 
apenas o fato de que - principalmente com o advento do Concretismo - o poema concreto rompeu com o lirismo e centrou sua atenção para o significante e a disposição gráfico-pictórica da peça, o que, pela curta análise empreendida aqui, não se sustenta. É necessário, então, ampliar-se o estudo da poesia visual.

\section{Referências}

Fontes:

CANCIONEIRO da Ajuda. [s.I.]: INCM, 1990. v. I.

CANCIONEIRO da Biblioteca Nacional. (Org.). Elza Paxeco Machado e José Pedro Machado. Lisboa: Edição da Revista de Portugal, 1949, vol. I.

CANCIONEIRO Geral de Garcia de Resende. Fixação do texto e estudo por Aida Fernanda Dias. Maia: Imprensa Nacional-Casa da Moeda, 1998. Volumes I a IV.

CANCIONEIRO Geral de Garcia de Resende. Nova edição preparada por A. J. Gonçalves Guimarães. Coimbra: Imprensa da Universidade, 1910-1917. Tomo I.

A POESIA lírica cultista e conceptista: colecção do século XVII, principalmente de Fênix Renascida. (Org.) Hernâni Cidade. 4 ed. Lisboa: Seara Nova, 1968.

Referências:

CAILLOIS, Roger. Los juegos y los hombres: la máscara y el vértigo. México. D.F.: Fondo de Cultura Económica, 1986.

CAMPOS, Augusto et alii. Teoria da poesia concreta. Textos críticos e manifestos. 19501960. [s.I.]: Livraria Duas Cidades, 1975. 
CIDADE, Hernâni. (Org.). A poesia lírica cultista e conceptista: colecção do século XVII, principalmente de Fênix Renascida. 4 ed. Lisboa: Seara Nova, 1968.

FONDA, Enio Aloisio. Maneirismos formais na poesia tardia. Revista de Letras, São Paulo, v. 25.

GARRIDO GÓMEZ, Elisa. Los juegos poéticos de Los Trovadores. Universidad de Sevilla, jun. 2002. Disponível em: <http://boek861.com/juego_poetico.htm>. Acesso em: 26 set. 2005.

HATHERLY, Ana. A experiência do prodígio. Bases teóricas e antologia de textos-visuais portugueses dos séculos XVII e XVIII. Lisboa: Imprensa Nacional-Casa da Moeda, 1983 (Temas Portugueses).

O prodígio da língua. II Colóquio Internacional Discursos e Práticas Alquímicas. Lisboa: Hugin Ed., 2002. Disponível em:

<http://www.triplov.com/alquimias/hatherly.htm>.

HAUSER, Arnold. Maneirismo: a crise da Renascença e o surgimento da Arte Moderna. 2 ed. Tradução de J. Guinsburg e M. França. São Paulo: Perspectiva, 1994.

HUIZINGA, Johan. Homo ludens. Tradução de João Paulo Monteiro. São Paulo: Perspectiva, 1993.

LE GOFF, Jacques. A civilização do ocidente medieval. Lisboa: Ed. Estampa, 1983. Vol. II). MAUÉS, Sheila. Percurso da visual da poesia ou a diacronia do moderno poético. ZUNAI Revista de poesia \& debates. Disponível em:

<http://www.revistazunai.com/ensaios/sheila_maues_diacronia.htm>. Acesso em: 2 maio 2017.

MELO E CASTRO, E. M. O próprio poético. (Ensaio de revisão da Poesia Portuguesa atual). São Paulo: Edições Quíron, 1973. (Série Crítica e História Literária).

MOISÉS, Massaud. As estéticas literárias em Portugal. Séculos XIV a XVIII. Lisboa: Caminho, 1997.

PETRARCA. Canzoniere. Torino: Einaudi, 1992. (Classici, 104).

PIGNATARI, Décio. Comunicação poética. São Paulo: Cortez \& Moraes, 1977. 
PONDIAN, Juliana Di Fiori. Technopaignia grega: o altar de Julius Vestinus. Praesentia, 10. Disponível em:

<http://erevistas.saber.ula.ve/index.php/praesentia/article/viewFile/3784/3627>. Acesso em: 2 maio 2017.

POUND, Ezra. $A B C$ da literatura. Tradução de Augusto de Campos e José Paulo Paes. São Paulo: Cultrix, 1998.

RIQUER, Martín de. Los trovadores. Historia literaria y textos. Barcelona: Ed. Ariel, S. A., 2001, Tomo I. Colección Letras e Ideas.

SÁ-CARNEIRO, Mário de. Obra completa. Rio de Janeiro: Aguilar, 1995.

ZÁRATE, Armando. Los textos visuales de la época alejandrina. Dispositio, Michigan, v. III, n. 9, otoño 1978.

ZUMTHOR, Paul. Carmina figurata. Tradução de. Alberto Alexandre Martins. Revista USP, n. 16, São Paulo, p. 69-76, 1992/1993.

\footnotetext{
'Paul Zumthor assim se manifesta quanto ao confronto grafismo versus desenho aplicados nos carmina figurata: "O grafismo, (...) como todo sistema de signos, tem dupla face: uma, o traçado das letras, voltada para o ponto de partida material; a outra, o desenho que engendra sua disposição, voltada para o sentido que se oferece à interpretação" (ZUMTHOR, 1992/1993, 75).

ii Expressão usada pelos poetas concretistas (cf. CAMPOS, 1975, 128 passim).

iii a análise do poema de Símias foi adaptada de: <http://www.revistazunai.com/ensaios/sheila_maues_diacronia.htm>. Acesso em: 2 maio 2017.

iv A poesia em forma de cálice aqui reproduzida encontra-se em Fonda, 1985, 119.

v Tome-se uma tradução esquemática dessa poesia figurada: "A escola fecha-se enfim / calam-se os preceptores / Vamo-nos enfim, / ledos errabundos / urge o descanso / [mas] dos óbolos carecemos. / Da venda dum Horácio, / plenos tornamos cálices: / canto / vinho / mulheres / a alma regeneramos / inflamam-nos as férias!" (AGNOLON, Alexandre. Poculum: tradução comentada. Mensagem eletrônica recebida por <geraldoaugust@uol.com.br>, em 6. out. 2005).

vi As análises dos poemas acima foram adaptadas de: <http://www.revistazunai.com/ensaios/sheila_maues_diacronia.htm>. Acesso em: 2 maio 2017.

vii “'Las leys d'amors' constituyen el mas extenso de nuestros tratados, de gran riqueza en sus partes gramaticales, retóricas, estilísticas y versificatorias, que si en algo pecan es por el exceso de noticias nimias y por el afán en clasificar y pormenorizar, pero que reúnen un auténtico tesoro de referencias". (RIQUER, 2001, I, 33-34). E, ainda, quanto ao uso das sílabas poéticas: "El cómputo de sílabas en principio siempre es
} 
exacto en la poesía trovadoresca, como es lógico en textos compuestos para ser cantados con una melodía culta y refinada" (idem, 36).

viii A tradução encontrada em Elisa Garrido Gómez é a seguinte: Hace un año que canto y voy considerando, y disponiendo, rimando, limando, alabando (y) amando los mandatos de afectos sin gozo. A autora inclui mais uma parte à poesia de Cerveri: "Ni a Sobrepetz, / Ne Is Cartz, / ne I Rey", que traduz por "En este canto no puedo incluir de ningún modo a Sobrepetz, a los Cardos ni al Rey" (GARRIDO GÓMEZ, 2002).

ix Essa cantiga-descordo de Nuneannes Cerzeo também aparece no Cancioneiro da Biblioteca Nacional. (Org.). Elza Paxeco Machado e José Pedro Machado. Lisboa: Edição da Revista de Portugal, 1949, vol. I, 192195.

× O descordo já era conhecido pelos trovadores provençais e "se caracteriza, como su nombre indica, por ser una composición en la que cada una de las estrofas tienen una fórmula métrica distinta, y por lo tanto también una melodía individual, lo que va en contra del rígido principio de isometría a que obedecen los demás géneros. Ello supone una gran variedad y riqueza de metros, rimas y melodías" (RIQUER, 2001, I, 49).

${ }^{\mathrm{xi}}$ In: CANCIONEIRO da Ajuda, 1990, I, 764-767.

xii Cf. CANCIONEIRO Geral de Garcia de Resende. 1910-1917, I, 205. Nessa transcrição, o português está atualizado.

xiii Com relação a este estilo em Portugal, comenta Jacques Le Goff: “o gótico 'manuelino' é, por volta de 1500 - uma das mais originais formas do delírio gótico - anuncia Gaudi” (LE GOFF, 1983. Vol. II, 131).

xiv Quanto a isso, diz Haroldo de Campos: "a POESIA CONCRETA é a linguagem adequada à mente criativa contemporânea / permite a comunicação em seu grau mais rápido / prefigura para o poema uma reintegração na vida cotidiana semelhante à que o BAUHAUS propiciou às artes visuais: quer como veículo de propaganda comercial (jornais, cartazes, TV, cinema, etc.), quer como objeto de pura fruição (funcionando na arquitetura, p. ex.), com campo de possibilidades análogo ao objeto plástico, substitui o mágico, o místico e o 'maudit' pelo ÚTIL” (CAMPOS, 1975, 47-48).

xv Disponível em: <http://www.instituto-camoes.pt/bases/literatura/experimentlsm.htm>. Acesso em: 2 maio 2017.

Recebido em 4 de novembro de 2017.

Aceito em 24 de janeiro de 2018. 